\title{
Power Quality Problems and New Solutions
}

\author{
A. de Almeida, L. Moreira. J. Delgado \\ ISR - Department of Electrical and Computer Engineering \\ University of Coimbra, Pólo II \\ 3030-290 Coimbra (Portugal) \\ phone: +351 239796 218, fax: +351239406 672 \\ e-mail: adealmeida@isr.uc.pt, licinio@isr.uc.pt, Jdelgado@elect.estv.ipv.pt.
}

\begin{abstract}
In this paper, the main Power Quality (PQ) problems are presented with their associated causes and consequences. The economic impacts associated with PQ are characterized. Finally, some solutions to mitigate the PQ problems are presented.
\end{abstract}

\section{Key words}

Power Quality, Power Quality problems, Power Quality costs, Power Quality solutions.

\section{Introduction}

Power Quality (PQ) related issues are of most concern nowadays. The widespread use of electronic equipment, such as information technology equipment, power electronics such as adjustable speed drives (ASD), programmable logic controllers (PLC), energy-efficient lighting, led to a complete change of electric loads nature. These loads are simultaneously the major causers and the major victims of power quality problems. Due to their non-linearity, all these loads cause disturbances in the voltage waveform.

Along with technology advance, the organization of the worldwide economy has evolved towards globalisation and the profit margins of many activities tend to decrease. The increased sensitivity of the vast majority of processes (industrial, services and even residential) to PQ problems turns the availability of electric power with quality a crucial factor for competitiveness in every activity sector. The most critical areas are the continuous process industry and the information technology services. When a disturbance occurs, huge financial losses may happen, with the consequent loss of productivity and competitiveness.

Although many efforts have been taken by utilities, some consumers require a level of PQ higher than the level provided by modern electric networks. This implies that some measures must be taken in order to achieve higher levels of Power Quality.

\section{Types of Power Quality Problems}

The most common types of Power Quality problems are presented in Table I.

\section{Power Quality Characterization}

Even the most advanced transmission and distribution systems are not able to provide electrical energy with the desired level of reliability for the proper functioning of the loads in modern society. Modern T\&D (transmission and distribution) systems are projected for 99,9 to $99,99 \%$ availability. This value is highly dependant of redundancy level of the network, which is different according to the geographical location and the voltage level (availability is higher at the HV network). In some remote sites, availability of T\&D systems may be as low as $99 \%$. Even with a $99,99 \%$ level there is an equivalent interruption time of 52 minutes per year.

The most demanding processes in the modern digital economy need electrical energy with $99.9999999 \%$ availability (9-nines reliability) to function properly.

Between 1992 and 1997, EPRI carried out a study in the US to characterize the average duration of disturbances. The result for a typical site, during the 6-year period is presented below.

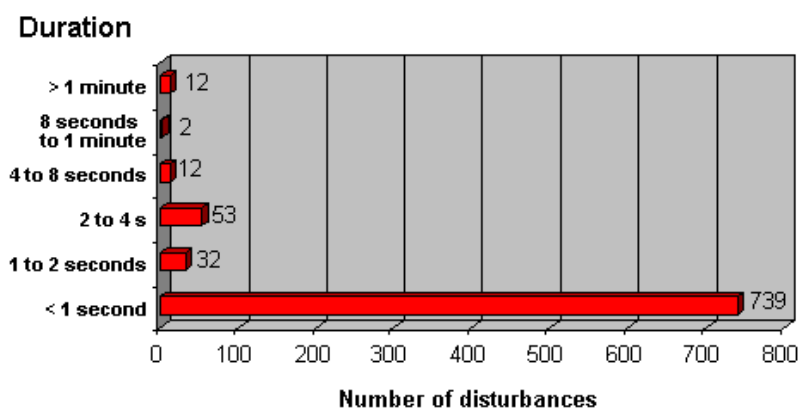

Fig. 1 - Typical distribution of PQ disturbances by its duration for a typical facility in 6 years (1992-97) in the US [2]. 


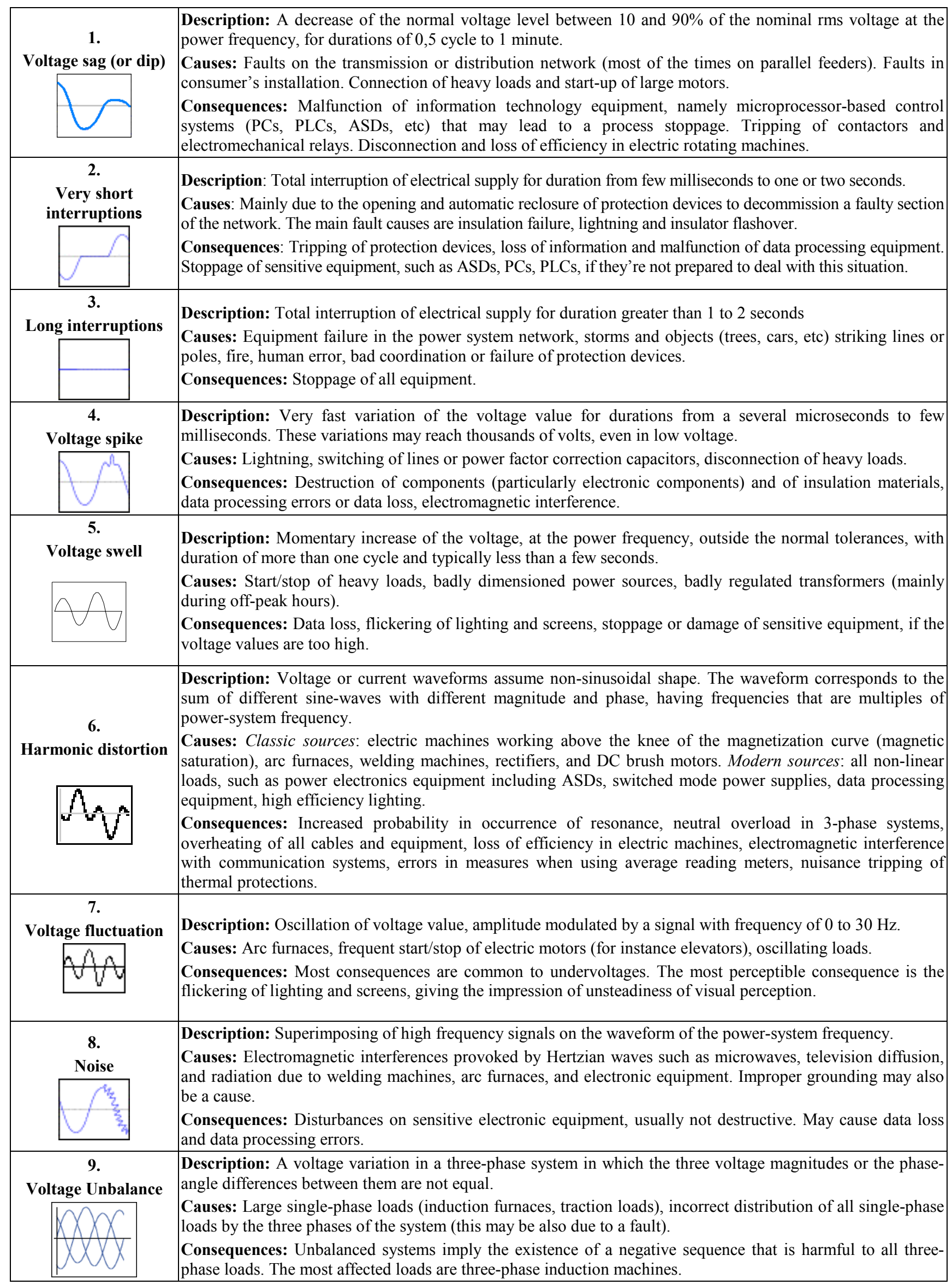


As it can be seen in Fig. 1., the vast majority of the disturbances registered (about 87\%) lasted less than 1 second and only 12 have duration greater than 1 minute. It is clear that not all these disturbances cause equipment malfunctioning, but many types of sensitive equipment may be affected.

Another study of EPRI was undertaken, between 1993 and 1999, in order to characterize the PQ on Low Voltage (LV) distribution networks. This study concluded that $92 \%$ of disturbances in PQ were voltage sags with amplitude drops up to $50 \%$ and duration below 2 seconds. Fig. 2 shows the typical distribution of sags under 0.5 seconds and micro-interruptions.

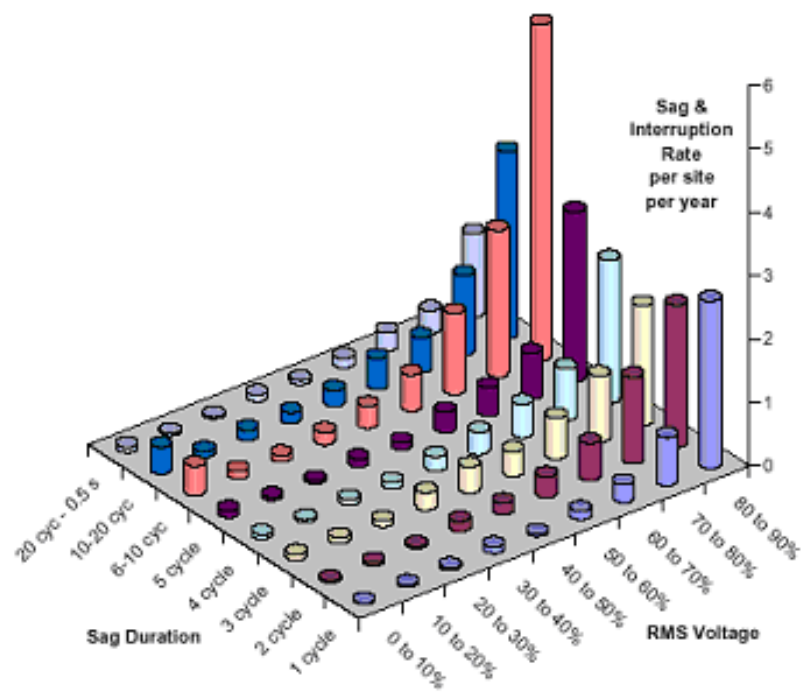

Fig. 2 - Distribution of sag and micro-interruption in LV networks in US [3].

The situation in developed countries of Europe is very similar to the one observed in the US. Fig. 3 shows the characterization of PQ in an industrial area of the center of Portugal by monitoring of the supply in the period February 2002-January 2003.

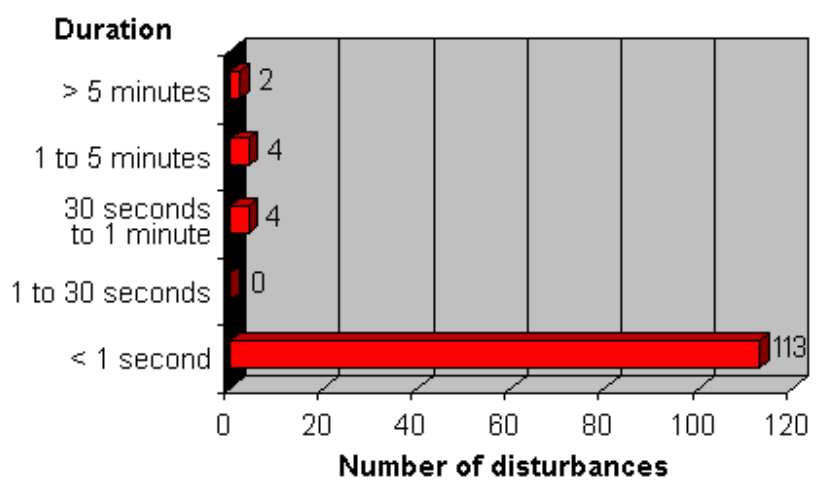

Fig. 3 - Characterization of electrical energy supply disturbances in an industrial facility in Portugal.

\section{Costs of Power Quality Problems}

The costs of PQ problems are highly dependant of several factors, mainly the business area of activity. Other factors, like the sensitivity of the equipment used in the facilities and market conditions, among other, also influence the costs of PQ problems.

\section{A. Power Quality Costs Evaluation}

The costs related to a PQ disturbance can be divided in:

1) Direct costs. The costs that can be directly attributable to the disturbance. These costs include the damage in the equipment, loss of production, loss of raw material, salary costs during non-productive period and restart costs. Sometimes, during the non-productive period some savings are achieved, such as energy savings, which must be subtracted to the costs. Some disturbances do not imply production stoppage, but may have other costs associated, such as reduction of equipment efficiency and reduction of equipment lifetime.

2) Indirect costs. These costs are very hard to evaluate. Due to some disturbances and nonproductive periods, one company may not be able to accomplish the deadlines for some deliveries and loose future orders. Investments to prevent power quality problems may be considered an indirect cost.

3) Non-material inconvenience. Some inconveniences due to power disturbance cannot be expressed in money, such as not listening to the radio or watch TV. The only way to account these inconveniences is to establish an amount of money that the consumer is willing to pay to avoid this inconvenience [4], [5].

\section{B. Estimates on Power Quality Costs}

Several studies have been made to evaluate the costs of PQ problems for consumers. The assessment of an accurate value is nearly impossible; so all these studies are based on estimates. Some of these studies are presented below.

1) Business Week (1991). PQ costs were estimated on 26,000 million USD per year in the United States.

2) EPRI (1994). This study pointed 400,000 million USD per year for PQ costs in the United States.

3) US Department of Energy (1995). PQ costs were estimated on 150,000 million USD per year for United States.

4) Fortune Magazine (1998). Stated that PQ costs were around 10,000 million USD per year in United States.

5) E Source (2001). A study comprising continuous process industries, financial services and food processing in the United States, estimated the average annual costs of PQ problems on 60,000 to 80,000 USD per installation.

6) $P Q$ costs in EU (2001). Overall PQ costs in industry and commerce, in European Union, are estimated in 10,000 million EUR per year [6]. 
The estimates of the various studies differ a lot, but all point to a common factor: the PQ costs are enormous.

\section{Costs of Momentary Interruptions}

An interruption is the $P Q$ problem with the most perceivable impact on facilities. Table II summarizes the typical costs of momentary interruptions (1 minute) for different types of consumers. The costs presented are without major investments in technologies to achieve ride-through capabilities to cope with the interruption. These values are based on published services and Electrotek Concepts experiences with individual studies $[5]$.

Table II - Typical costs of momentary interruptions (1 minute, in $\$ / \mathrm{kW}$ demand, for different types of industrial and services facilities.

\begin{tabular}{|c|c|c|}
\hline & \multicolumn{2}{|c|}{$\begin{array}{l}\text { Cost of momentary } \\
\text { interruption } \\
\text { (\$/kW demand) }\end{array}$} \\
\hline & Maximum & Minimum \\
\hline \multicolumn{3}{|l|}{$\begin{array}{l}\text { Industrial } \\
\end{array}$} \\
\hline Automobile manufacturing & 5.0 & 7.5 \\
\hline Rubber and plastics & 3.0 & 4.5 \\
\hline Textile & 2.0 & 4.0 \\
\hline Paper & 1.5 & 2.5 \\
\hline Printing (newspapers) & 1.0 & 2.0 \\
\hline Petrochemical & 3.0 & 5.0 \\
\hline Metal fabrication & 2.0 & 4.0 \\
\hline Glass & 4.0 & 6.0 \\
\hline Mining & 2.0 & 4.0 \\
\hline Food processing & 3.0 & 5.0 \\
\hline Pharmaceutical & 5.0 & 50.0 \\
\hline Electronics & 8.0 & 12.0 \\
\hline Semiconductor manufacturing & 20.0 & 60.0 \\
\hline \multicolumn{3}{|l|}{ Services } \\
\hline $\begin{array}{l}\text { Communication, information } \\
\text { processing }\end{array}$ & 1.0 & 10.0 \\
\hline Hospitals, banks, civil services & 2.0 & 3.0 \\
\hline Restaurants, bars, hotels & 0.5 & 1.0 \\
\hline Commercial shops & 0.1 & 0.5 \\
\hline
\end{tabular}

As it can be seen, the industrial sector is the most affected by interruptions, especially the continuous process industry. In the services sector, communication and information processing is the most affected business area.

The costs of interruptions are also function of its duration. Fig. 4 depicts the costs of interruptions against its duration.

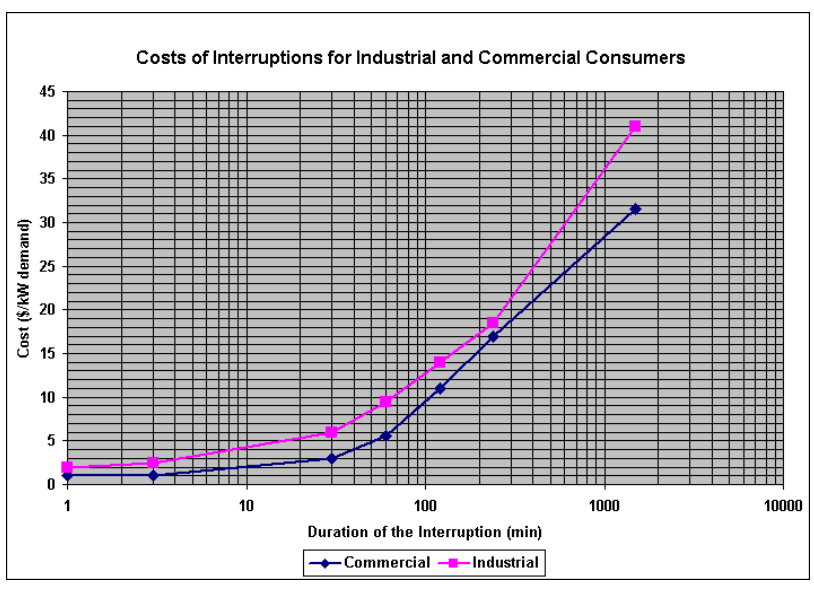

Fig. 4 - Costs of interruptions as function its duration [5].

\section{Solutions for PQ Problems}

The mitigation of PQ problems may take place at different levels: transmission, distribution and the enduse equipment. As seen in Fig. 5, several measures can be taken at these levels.

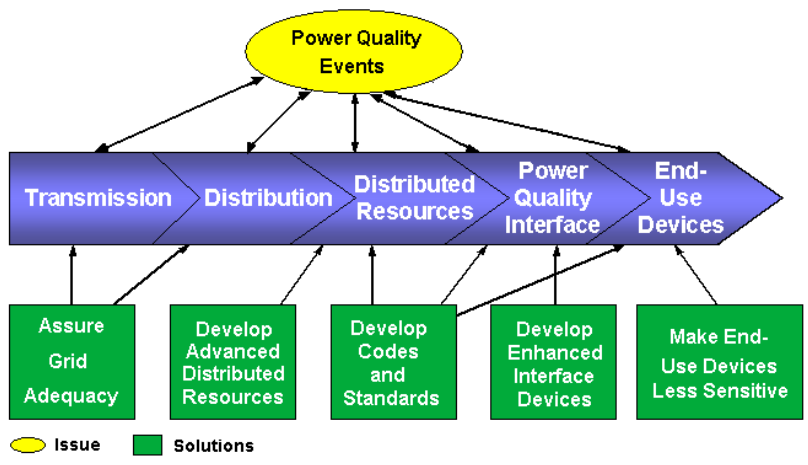

Fig. 5 - Solutions for digital power [7]

\section{Grid Adequacy}

Many PQ problems have origin in the transmission or distribution grid. Thus, a proper transmission and distribution grid, with adequate planning and maintenance, is essential to minimize the occurrence of PQ problems.

\section{Distributed Resources - Energy Storage Systems}

Interest in the use of distributed energy resources (DER) has increased substantially over the last few years because of their potential to provide increased reliability. These resources include distributed generation and energy storage systems.

Energy storage systems, also known as restoring technologies, are used to provide the electric loads with ride-through capability in poor PQ environment. 


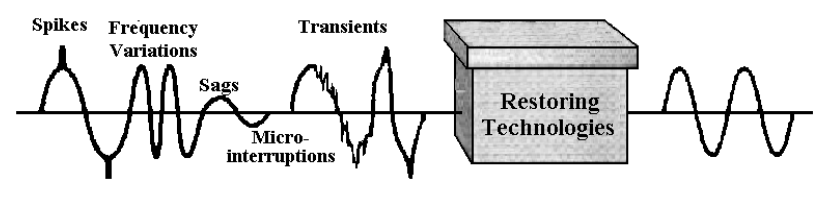

Fig. 6 - Restoring technologies principle [1].

Recent technological advances in power electronics and storage technologies are turning the restoring technologies one of the premium solutions to mitigate PQ problems.

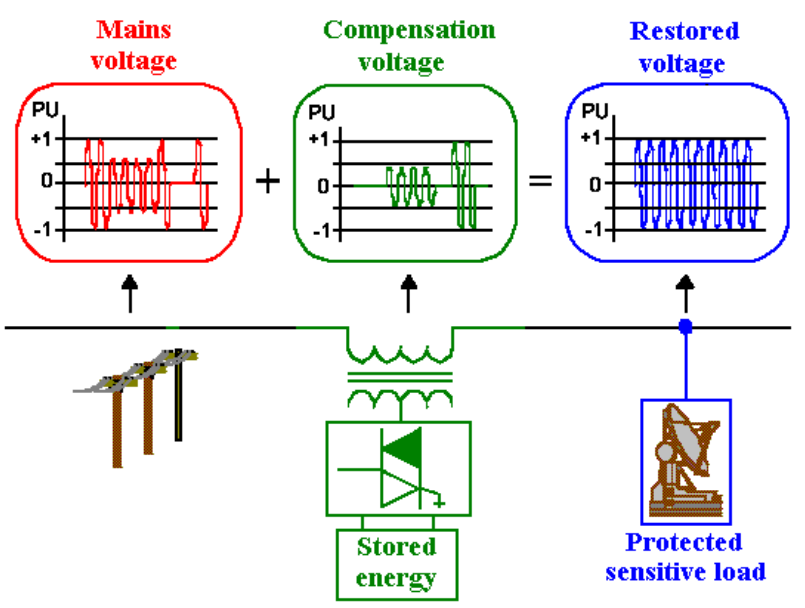

Fig. 7 - Working principle of an energy storage system.

The first energy storage technology used in the field of PQ, yet the most used today, is electrochemical battery. Although new technologies, such as flywheels, supercapacitors and superconducting magnetic energy storage (SMES) present many advantages, electrochemical batteries still rule due to their low price and mature technology.

\section{A. Flywheels}

A flywheel is an electromechanical device that couples a rotating electric machine (motor/generator) with a rotating mass to store energy for short durations. The motor/generator draws power provided by the grid to keep the rotor of the flywheel spinning. During a power disturbance, the kinetic energy stored in the rotor is transformed to DC electric energy by the generator, and the energy is delivered at a constant frequency and voltage through an inverter and a control system. Fig. 8 depicts the scheme of a flywheel, where the major advantages of this system are explained.

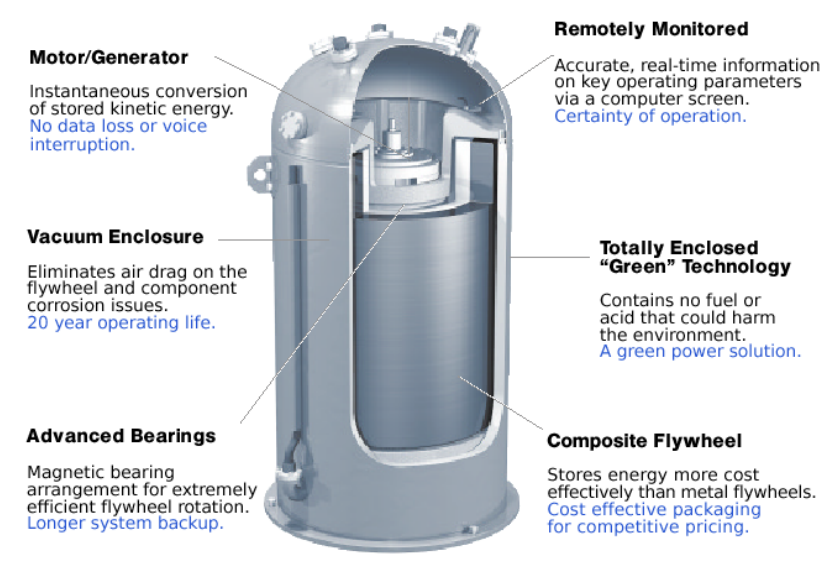

Fig. 8 - Flywheel [http://www.beaconpower.com]

Traditional flywheel rotors are usually constructed of steel and are limited to a spin rate of a few thousand revolutions per minute (RPM). Advanced flywheels constructed from carbon fibre materials and magnetic bearings can spin in vacuum at speeds up to 40,000 to 60,000 RPM. The stored energy is proportional to the moment of inertia and to the square of the rotational speed. High speed flywheels can store much more energy than the conventional flywheels.

The flywheel provides power during a period between the loss of utility supplied power and either the return of utility power or the start of a back-up power system (i.e., diesel generator). Flywheels typically provide 1-100 seconds of ride-through time, and back-up generators are able to get online within 5-20 seconds.

\section{B. Supercapacitors}

Supercapacitors (also known as ultracapacitors) are DC energy sources and must be interfaced to the electric grid with a static power conditioner, providing energy output at the grid frequency. A supercapacitor provides power during short duration interruptions or voltage sags.

Medium size supercapacitors (1 MJoule) are commercially available to implement ride-through capability in small electronic equipment, but large supercapacitors are still in development, but may soon become a viable component of the energy storage field.

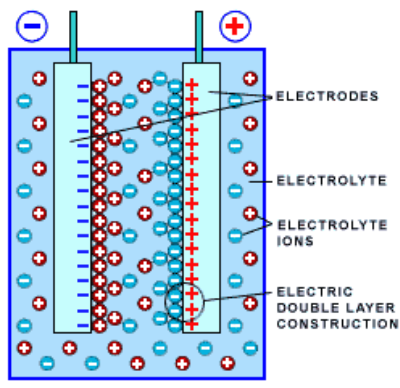

Fig. 9 - Electric double layer supercapacitor [http://www.esmacap.com]

Capacitance is very large because the distance between the plates is very small (several angstroms), and because 
the area of conductor surface (for instance of the activated carbon) reaches $1500-2000 \mathrm{~m}^{2} / \mathrm{g}$ (16000-21500 $\mathrm{ft}^{2} / \mathrm{g}$ ). Thus, the energy stored by such capacitors may reach $50-60 \mathrm{~J} / \mathrm{g}[8]$.

\section{SMES}

A magnetic field is created by circulating a DC current in a closed coil of superconducting wire. The path of the coil circulating current can be opened with a solid-state switch, which is modulated on and off. Due to the high inductance of the coil, when the switch is off (open), the magnetic coil behaves as a current source and will force current into the power converter which will charge to some voltage level. Proper modulation of the solid-state switch can hold the voltage within the proper operating range of the inverter, which converts the DC voltage into AC power.

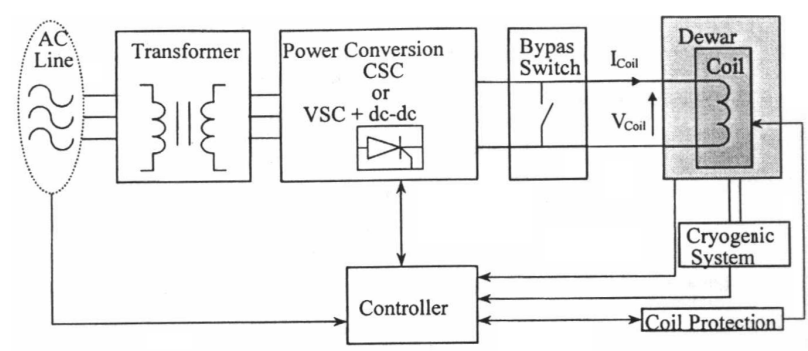

Fig. 10 - SMES system [9].

Low temperature SMES cooled by liquid helium is commercially available. High temperature SMES cooled by liquid nitrogen is still in the development stage and may become a viable commercial energy storage source in the future due to its potentially lower costs.

SMES systems are large and generally used for short durations, such as utility switching events.

\section{Comparison of Storage Systems}

Fig. 11 shows a comparison of the different storage technology in terms of specific power and specific energy.

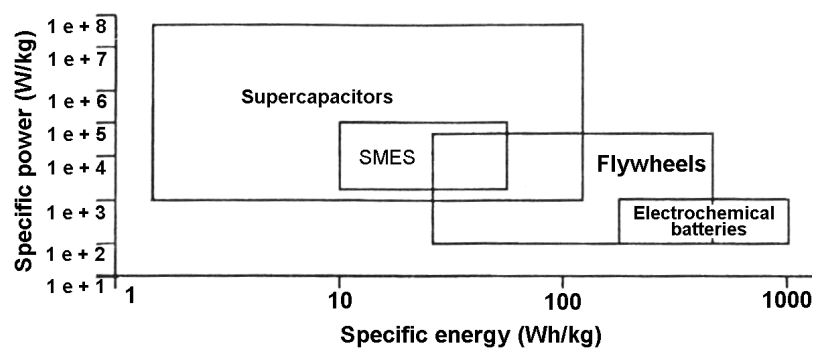

Fig. 11 - Specific power versus specific energy ranges for storage technologies [9].

Fig. 12 shows the specific costs of energy storage devices.

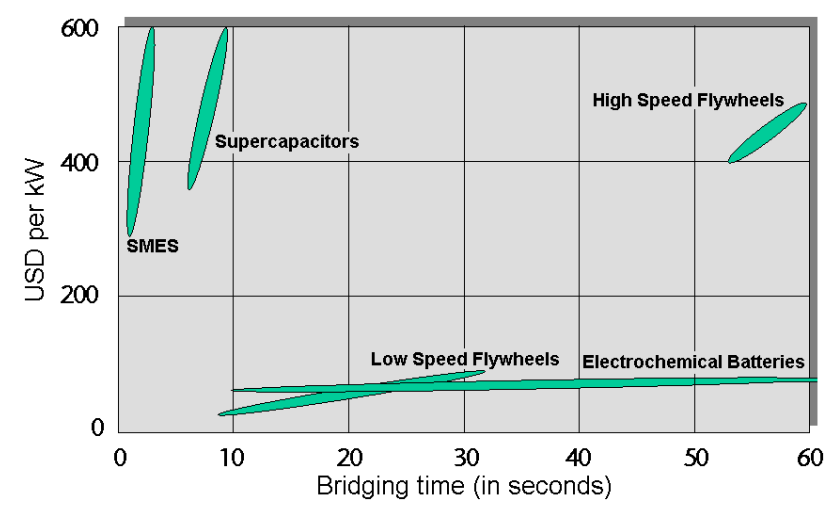

Fig. 12 - Specific costs of energy storage devices [10].

The high speed flywheel is in about the same cost range as the SMES and supercapacitors and about 5 times more expensive than a low speed flywheel due to its more complicated design and limited power rating. Electrochemical battery has a high degree of mature and a simple design. Below a storage time of 25 seconds the low speed flywheel can be more cost effective than the battery.

\section{Distributed Resources - Distributed Generation}

Distributed Generation (DG) units can be used to provide clean power to critical loads, isolating them from disturbances with origin in the grid. DG units can also be used as backup generators to assure energy supply to critical loads during sustained outages. Additionally DG units can be used for load management purposed to decrease the peak demand.

At present, reciprocating engine is the prevalent technology in DG market, but with technology advancements, other technologies are becoming more attractive, such as microturbines or fuel cells (Table III).

Table III - Evolution of DG technologies.

\begin{tabular}{|c|c|c|c|}
\hline & \begin{tabular}{|l|} 
Reciprocating \\
Engines
\end{tabular} & Microturbines & Fuel Cells \\
\hline Timing & - Ongoing & $\begin{array}{l}\text { - Emerging } \\
\text { now }\end{array}$ & - Mid-200’s \\
\hline Market & $\begin{array}{r}\text { - Standby/back } \\
\text { up utilization }\end{array}$ & $\begin{array}{l}\text { - Peak-shaving } \\
\text { and PQ }\end{array}$ & $\begin{array}{l}\text { - Prime power } \\
\text { and PQ }\end{array}$ \\
\hline Economics & 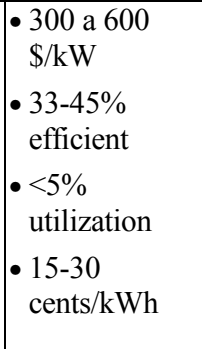 & $\begin{array}{l}\cdot 750 \$ / \mathrm{kW} \\
\cdot 20-30 \% \\
\text { efficient } \\
\bullet \sim 20 \% \\
\text { utilization } \\
\bullet 10-15 \\
\text { cents } / \mathrm{kWh}\end{array}$ & $\begin{array}{l}\bullet 1000 * \text { a } 4000 \\
\$ / \mathrm{kW} \\
\bullet 45-60 \% \\
\text { efficient } \\
\bullet>80 \% \\
\text { utilization } \\
\bullet 5 * \text { cents } / \mathrm{kWh} \\
\\
* \text { predicted }\end{array}$ \\
\hline
\end{tabular}

If DG units are to be used as back-up generation, a storage unit must be used to provide energy to the loads during the period between the origin of the disturbance and the start-up of the emergency generator. 
The most common solution is the combination of electrochemical batteries UPS and a diesel genset. At present, the integration of a flywheel and a diesel genset in a single unit is also becoming a popular solution, offered by many manufacturers.

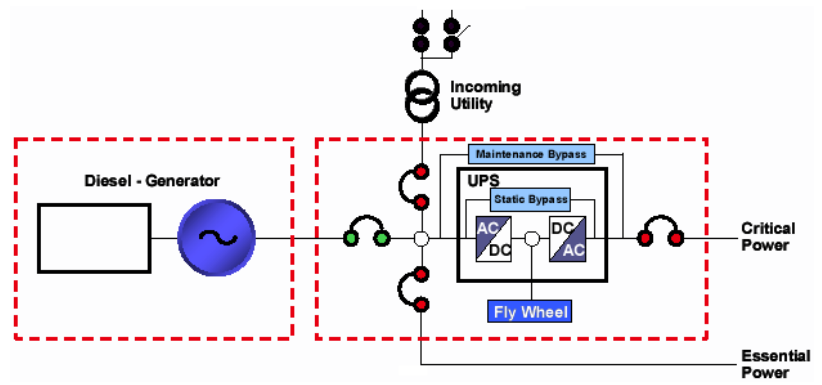

Fig. 13 - Scheme of a continuous power system, using a flywheel and a diesel genset [www.geindustrialsystems.com].

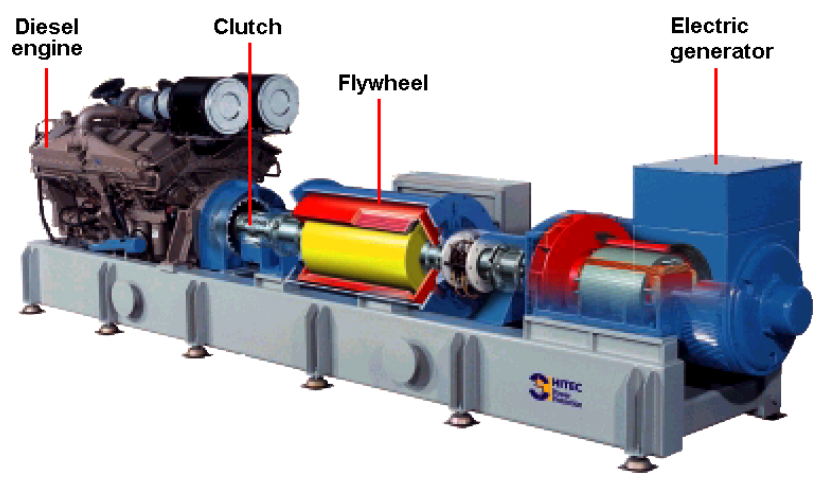

Fig. 14 - Dynamic UPS, by Hitec Power Protection, bv. [http://www.hitec-ups.com].

\section{Enhanced Interface Devices}

Besides energy storage systems and DG, some other devices may be used to solve PQ problems.

Using proper interface devices, one can isolate the loads from disturbances deriving from the grid.

\section{A. Dynamic Voltage Restorer}

A dynamic voltage restorer (DVR) acts like a voltage source connected in series with the load. The working principle of the most common DVRs is similar to Fig. 7. The output voltage of the DVR is kept approximately constant voltage at the load terminals by using a step-up transformer and/or stored energy to inject active and reactive power in the output supply trough a voltage converter.

\section{B. Transient Voltage Surge suppressors (TVSS)}

Transient voltage surge suppressors are used as interface between the power source and sensitive loads, so that the transient voltage is clamped by the TVSS before it reaches the load. TVSSs usually contain a component with a nonlinear resistance (a metal oxide varistor or a zener diode) that limits excessive line voltage and conduct any excess impulse energy to ground.

\section{Constant Voltage Transformers}

Constant voltage transformers (CVT) were one of the first PQ solutions used to mitigate the effects of voltage sags and transients. To maintain the voltage constant, they use two principles that are normally avoided: resonance and core saturation.

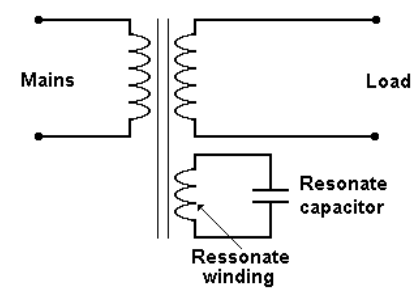

Fig. 15 - Constant voltage transformer.

When the resonance occurs, the current will increase to a point that causes the saturation of the magnetic core of the transformer. If the magnetic core is saturated, then the magnetic flux will remain roughly constant and the transformer will produce an approximately constant voltage output.

If not properly used, a CVT will originate more PQ problems than the ones mitigated. It can produce transients, harmonics (voltage wave clipped on the top and sides) and it is inefficient (about $80 \%$ at full load). Its application is becoming uncommon due to technological advances in other areas.

\section{Noise Filters}

Noise filters are used to avoid unwanted frequency current or voltage signals (noise) from reaching sensitive equipment. This can be accomplished by using a combination of capacitors and inductances that creates a low impedance path to the fundamental frequency and high impedance to higher frequencies, that is, a low-pass filter. They should be used when noise with frequency in the $\mathrm{kHz}$ range is considerable.

\section{E. Isolation Transformers}

Isolation transformers are used to isolate sensitive loads from transients and noise deriving from the mains. In some cases (Delta-Wye connection) isolation transformers keep harmonic currents generated by loads from getting upstream the transformer.

The particularity of isolation transformers is a grounded shield made of nonmagnetic foil located between the primary and the secondary. Any noise or transient that come from the source in transmitted through the capacitance between the primary and the shield and on to the ground and does not reach the load. 


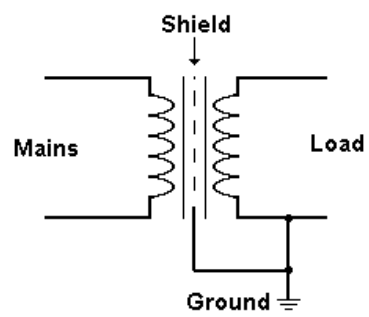

Fig. 16 - Isolation transformer.

\section{F. Static VAR Compensators}

Static VAR compensators (SVR) use a combination of capacitors and reactors to regulate the voltage quickly. Solid-state switches control the insertion of the capacitors and reactors at the right magnitude to prevent the voltage from fluctuating. The main application of SVR is the voltage regulation in high voltage and the elimination of flicker caused by large loads (such as induction furnaces).

\section{G. Harmonic Filters}

Harmonic filters are used to reduce undesirable harmonics. They can be divided in two groups: passive filters and active filters.
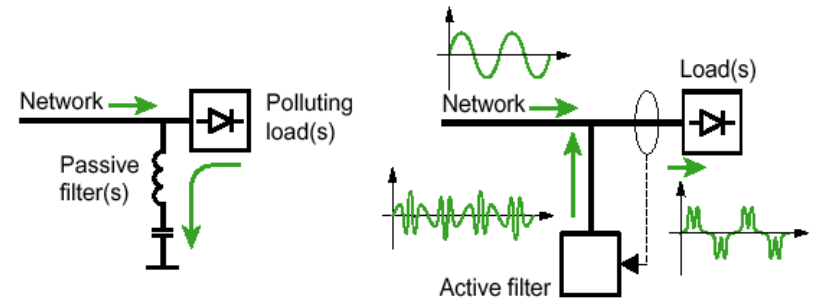

Fig. 17 - Harmonic filters [11].

Passive filters (Fig. 17 left) consist in a low impedance path to the frequencies of the harmonics to be attenuated using passive components (inductors, capacitors and resistors). Several passive filters connected in parallel may be necessary to eliminate several harmonic components. If the system varies (change of harmonic components), passive filters may become ineffective and cause resonance.

Active filters (Fig. 17 right) analyse the current consumed by the load and create a current that cancel the harmonic current generated by the loads. Active filters were expensive in the past, but they are now becoming cost effective compensating for unknown or changing harmonics.

\section{Develop Codes and Standards}

Some measures have been taken to regulate the minimum PQ level that utilities have to provide to consumers and the immunity level that equipment should have to operate properly when the power supplied is within the standards.

One major step in this direction was taken with the CBEMA curve (Fig 18), created by the Computer and
Business Equipment Manufacturer's Association. This standard specifies the minimum withstanding capability of computer equipment to voltage sags, microinterruptions and overvoltages.

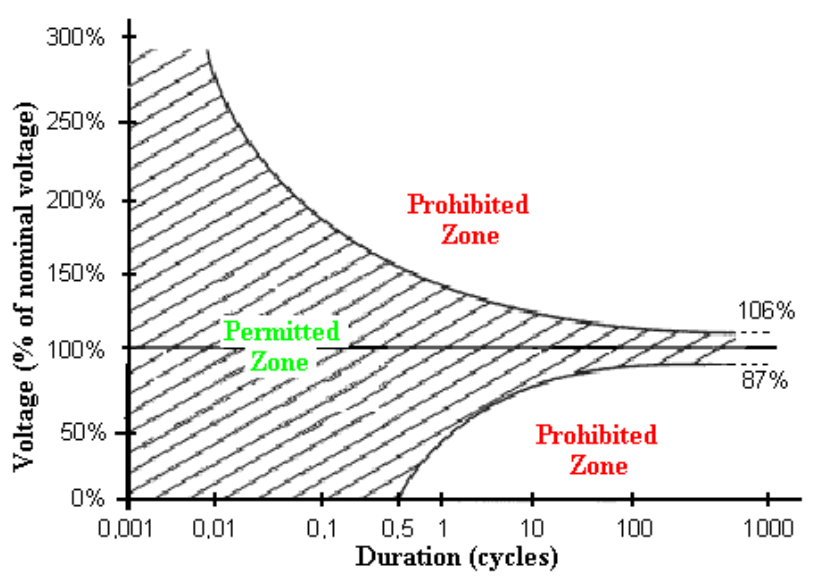

Fig. 18 - CBEMA curve.

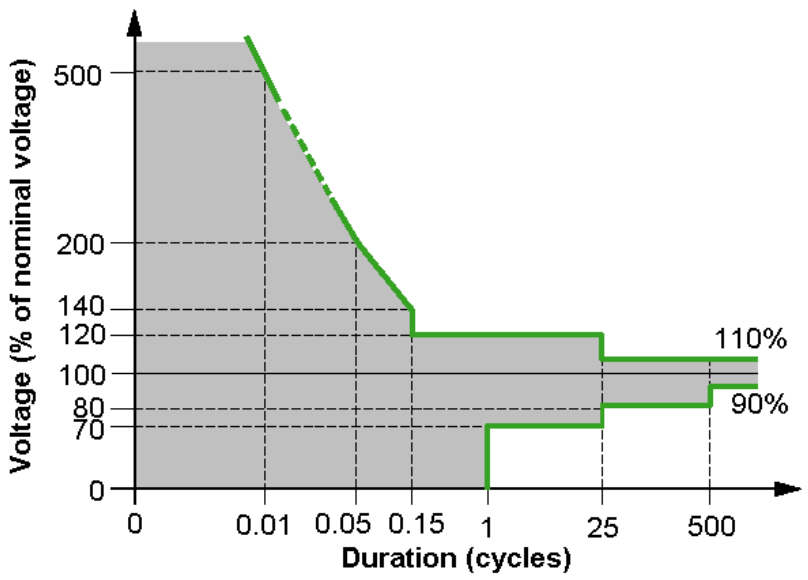

Fig. 19 - ITIC curve

This curve, although substituted recently by ITIC (Information Technology Industry Council) curve (Fig. 19), is still a reference in the area of PQ. When the voltage is within the limits determined by the shaded zone, the equipment should function normally. When the voltage is comprised on the zone below the permitted zone, the equipments may malfunction or stop. When the voltage is comprised in the upper prohibited zone, besides equipment malfunction, damage on the equipment may occur.

Other standardization organizations (IEC, CENELEC, IEEE, etc) have developed a set of standards with the same purposes. In Europe, the most relevant standards in PQ are the EN 50160 (by CENELEC) and IEC 61000. 
Table IV - Most important parameters defined by European Norm 50160:2001.

\begin{tabular}{|c|c|}
\hline \\
\hline & Limits \\
\hline Frequency & $\begin{array}{l}\text { Must remain between } 49.5(\mathbf{- 1 \% )} \text { and } 50.5 \\
(\mathbf{+ 1 \% )} \mathrm{Hz} \text {. }\end{array}$ \\
\hline Voltage & $\begin{array}{l}\text { The voltage must be between } 90 \% \text { and } \\
110 \% \text { of nominal voltage. }\end{array}$ \\
\hline $\begin{array}{l}\text { Voltage } \\
\text { Unbalance }\end{array}$ & $\begin{array}{l}\text { The negative sequence cannot assume } \\
\text { magnitude higher than } \mathbf{2 \%} \text { of the direct } \\
\text { sequence. }\end{array}$ \\
\hline $\begin{array}{l}\text { Harmonic } \\
\text { voltage }\end{array}$ & $\begin{array}{l}\text { THD }<8 \% \\
V_{3}<5.0 \% \\
V_{5}<6.0 \% \\
\text { V7 }<5.0 \%\end{array}$ \\
\hline
\end{tabular}

\section{Make End-use Devices Less Sensitive}

Designing the equipment to be less sensitive to disturbances is usually the most cost effective measure to prevent PQ problems. Some manufacturers of end-use equipment are now recognising this problem, but the competitive market means that manufacturers should reduce costs and only respond to customers' requirements. The exception is the ASD market, where manufacturers are actively promoting products with enhanced ride-through capabilities.

Adding a capacitor with a larger capacity to power supplies, using cables with larger neutral conductors, derating transformers and adjusting undervoltage relays, are measures that could be taken by manufacturers to reduce the sensitivity of equipment to PQ problems.

\section{Conclusions}

The availability of electric power with high quality is crucial for the running of the modern society. If some sectors are satisfied with the quality of the power provided by utilities, some others are more demanding.

To avoid the huge losses related to PQ problems, the most demanding consumers must take action to prevent the problems. Among the various measures, selection of less sensitive equipment can play an important role. When even the most robust equipment is affected, then other measures must be taken, such as installation of restoring technologies, distributed generation or an interface device to prevent PQ problems.

\section{References}

[1] J. Delgado, "Gestão da Qualidade Total Aplicada ao Sector do Fornecimento da Energia Eléctrica", Thesis submitted to fulfilment of the requirements for the degree of $\mathrm{PhD}$. in Electrotechnical Engineering, Coimbra, September 2002.

[2] "The Two Seconds Problem", American Superconductor and EPRI Research, March 1998.

[3] EPRI Power Delivery Group, "The Future of Power Delivery in the $21^{\text {st }}$ Century", 1999.

[4] M. Bollen, "Understanding Power Quality Problems - Voltage Sags and Interruptions", IEEE Press Series on Power Engineering - John Wiley and Sons, Piscataway, USA (2000).

[5] M. McGranaghan, "Costs of Interruptions", in proceedings of the Power Quality 2002 Conference, Rosemont, Illinois, pp 1-8, October 2002..

[6] D. Chapman, "Costs of Poor Power Quality", Power Quality Application Guide - Copper Development Association, March 2001.

[7] EPRI, "Creating the Electricity Infrastructure for a Digital Society", UIE-2000 Conference, Lisbon, 13, November 2000.

[8] http://www.esma-cap.com

[9] P. Ribeiro, B. Johnson, M. Crow, A. Arsoy, Y. Liu, "Energy Storage Systems for Advanced Power Applications", Proceedings of the IEEE, vol 89, no. 12, December 2001.

[10] H. Darrelmann, "Comparison of Alternative Short Time Storage Systems”, Piller, GmbH, Osterode, Germany.

[11] P. Ferracci, “ Power Quality”, Schneider Electric Cahier Technique no. 199, September 2000. 